\title{
Analysis of Phonetic Fossilization in Chinese Students' English Interlanguage Based on Conceptual Integration Theory
}

\author{
Xuexin Du \\ Nanyang Institute of Technology, Nanyang, Henan Province, China \\ moonriverr@163.com
}

Keywords: Interlanguage, Phonetic Fossilization, Conceptual Integration Theory

\begin{abstract}
The American linguist Larry Selinker proposed the concept of interlanguage in 1972, after which scholars have conducted extensive research on the pronunciation, vocabulary, syntax, discourse and pragmatics of interlanguage from different perspectives. This paper analyzes the result of a phonetic test for English majors of Chinese students according to conceptual integration theory in cognitive linguistics, aiming to find out the characteristics of phonetic fossilization in Chinese learners and its cognitive mechanism. Finally, the paper tries to propose the strategies to accelerate the transformation of phonetic fossilization.
\end{abstract}

\section{Introduction}

The concept of interlanguage proposed by American linguist Selinker (1972) [1] refers to the transitional language system between the mother language and the target language used by learners in the process of foreign language learning. The learner's interlanguage system starts with the mother tongue and gradually approaches the target language. Scholars have conducted extensive research on the aspects of pronunciation, vocabulary, syntax, discourse, and pragmatics of interlanguage from different perspectives. However, phonology fossilization is rarely studied based on the conceptual integration theory.

This paper obtains the spoken English data from a phonetic test of 32 undergraduates majoring in English in a college in China and applies the conceptual integration theory to the analysis of phonetic fossilization. This research is expected to find out the cognitive mechanism of phonetic fossilization of Chinese students, thus providing a new perspective for interlanguage research.

\section{Mental spaces and conceptual integration networks}

Conceptual integration theory is developed by Gilles Fauconnier and Mark Turner on the basis of their mental space theory. "Mental spaces are very partial assemblies constructed as we think and talk, for purposes of local understanding and action. They contain elements and are structured by frames and cognitive models" (Fauconnier G, Turner M B, 2008) [2]. Mental spaces are conceptual packets formed in human minds in the course of their communication. There are many types of concepts inside the packets including more general knowledge. Some elements in the two input spaces map into each other according to some principles. "Mental spaces are constructed and modified as thought and discourse unfolds and are connected to each other by various kinds of mappings, in particular identity and analogy mappings" (Fauconnier G, Turner M B,2008) [2].

Fauconnier and Turner $(2003,58)$ hold that there are four mental spaces-input space I, input space II, generic space and blended space-during the process of construction of language [3]. Generic Space contains the shared construction and common information during the mapping. Blended space goes through three processes called composition, completion and extension on the basis of cross-space mapping and the final product which is different from any of the input pace is formed.

Conceptual integration theory is the interpretation of the process of mapping of each mental space. They believe that conceptual integration is a universal principle of human cognition. This 
theory can be used to reveal the cognitive mechanism of the on-line construction of linguistic form or meaning. There are various types of conceptual integration networks, such as simplex networks, mirror networks, single-scope networks and double-scope networks (Fauconnier, 1998:42-45) [4].

\section{Mechanism of Phonetic Fossilization}

The author tests the junior English majors in China with Lesson Two in New Concept English III. Each of their speech is recorded by the software Goldwave. Analysis reveals four characteristics of their phonetic fossilization: phone replacement, phone addition, phone omission and rhythmic mistakes. When analyzed according to the conceptual integration theory, results suggest Chinese students' phonetic fossilization is formed mainly through one-scope network integration.

In the light of Fauconnier \& Turner's four mental-space model, the author holds that four specific spaces are involved when Chinese students are producing their speech: input space I (Chinese phonetic system), input space II (English phonetic system), generic space and blended space. The most frequent mapping between mental spaces is identity mapping and analogical mapping, in which similar phonetic elements in the two spaces are identified and the counterparts are mapped into each other; hence, the sound in Chinese which is similar to a certain sound in English is projected into the blended space. So do the other phonetic characteristics or phonological rules in Chinese. Chinese phonetic system functions as the framework governing the cross-space mapping and the integration of phonetic segments in the blended space. Finally, speech with sounds both different from the Chinese phonetic system and English phonetic system is formed.

The following are cognitive mechanism of each type of phonetic fossilization.

(1) Phone replacement

The speech record in Goldwave shows twelve students pronounce [ð]in the word then as[z], five students pronounce [v] in the word never as [w], and fifteen students pronounce [ $\theta$ ] in the word thirteen as [s], etc. These cases are collectively called phone replacement.

Phone replacement in Chinese students results from the mapping of finals into vowels and initials into consonants. According to Wang (2009) [5], mappings are made because of the relation between the two input spaces. He holds that the main relation types are cause and effect, temporal relation, spatial relation and identity correlation, etc. When Chinese students compare Chinese and English, they find that the a few initials sound like some consonants in English and finals, vowels. Consequently English beginners build identity correlation between constants and initials and that between vowels and finals. As a result, phonemes in Chinese find a way to enter the blending process. Hence, during the integration process, phones in Chinese which are similar to English ones take the place of English phones.

In case of the word thirteen, since there is no fricative [ $\theta]$ in Chinese, but there is a very similar sound-supradental [s] in it. Phone replacement happens naturally for some students who practice less of $[\theta]$ sound in English.

(2) Phone addition

Another phonetic fossilization reveals the addition of phones. Five students pronounce the word at [æt] as [ætə]. Two students pronounce the word afraid [ə'freId] as [ə'freIdə].

From the careful observation, the author finds that phone addition usually happens in the words with consonant cluster or words ending with a consonant. When a Chinese student pronounces this type of sounds, there are four mental spaces formed in his mind: input space I (Chinese syllable structure), input space II (English syllable structure), generic space and blended space. The integration network is single-scope network. For students with fossilization of sounds, only Chinese syllable structure is projected into the blended space, governing the pronunciation of the word and hence the result of the integration.

The frequently seen syllabic structure of English is CVC (consonant + vowel + consonant). $\mathrm{CV}$ and $\mathrm{V}$ are other types of English syllable. There are three consonants at most on the onset, for example, sprint. There may be as many as four consonants in the 
coda, for instance, sixths. By contrast, Most Chinese syllabic structure follows the pattern: 'initial + final', quite like some of the syllabic structure CV (consonant + vowel) in English. In addition, there are less consonant clusters (except nasal finals) in Chinese.

Since the framework responsible for the combination of each individual sound for lower level English learners is mainly 'initial + final' structure, English consonant cluster judged in terms of Chinese syllabic structure is illegal. These learners influenced so much by Chinese tend to add a frequently used English vowel like /i:/ or /a/ from input space system II(English phonetic system)to the existing consonant in it, resulting in an emergent syllable (originally only a consonant), say, [æt] is pronounced *[ætə].

(3) Phone omission

There are two types of phone omission. One is the omission of a certain consonant in the consonant cluster. For example, five students pronounce the word probably ['probəbli] as *['probəli]. The other is the omission of a certain vowel in a vowel cluster. For instance, three student omit [ə] in the word our [avo].

According to the conceptual integration theory, mental spaces are containers filled with elements of speech, which are supervised by a certain frame. English learners, influenced by his native language, unconsciously allow Chinese phonetic system enter the blended space and be responsible for the integration of the elements in the two input spaces. The syllabic structure in Chinese is mainly 'initial + final' (except nasal initials) and there is almost no consonant cluster or vowel cluster. Therefore, in the course of integration, the consonant cluster or vowel cluster doesn't fit into the rule of standard mandarin. Hence, the "redundant" sound is excluded from the integration by English beginners of Chinese students. As a result, phone omission happens. The pronunciation of probably ['probəbli] becomes *['probəli].

(4) Rhythm mistakes

The characteristics of phonetic fossilization in the English interlanguage in suprasegmentals include: the error of word stress and the error of sentence rhythm, etc., among which the latter is the most obvious. The English sentence tone pronounced by 16 students is very mundane, even with stress for each word, making the sentences sound unrhythmical and short of beauty of English language. The phonetic interlanguage is quite different from the rhythmical English sentences.

The reason for rhythm errors is also the result of one-scope network integration. When a student is reading a sentence, there are four mental spaces his mind: input space I (Chinese rhythm space), input space II (English rhythm space), generic space, and integration space. According to Xu (2005) [6], the rhythm of the Chinese sentence is syllable-timed, while English is a stress-timed rhythm, a rhythm based on accented syllable intervals.

Rhythm knowledge is a system known to Chinese learners and is projected into the blended space as the integration framework. At the same time, the characteristics of spoken English such as stress are also projected into the generic space.

Chinese syllable rhythm is the integration frame for beginners in reading a sentence. The pitch of words (except function word) of a sentence must be different, with some sounds low and some high, some with stress and some without. Affected by Chinese syllable rhythm in the input mental space, the lower leveled Chinese students' output of the English sentence sounds word-breaking, with most words stressed, unlike English rhythm which can gives people the feeling that it is a series of beautiful rhythms and timed syllables.

\section{Conclusion}

Based on the conceptual integration theory, through the analysis of a speech test, it is found that the phonetic fossilization of English majors is mainly reflected in phone replacement, phone addition, phone omission, and rhythm mistakes. The cognitive mechanism of the occurrence of the phonetic interlanguage lies mainly in the integration of the knowledge of the native language speech systems into the blended space, which becomes the organizational frame for conceptual integration and 
dominates the process of speech integration.

How can students avoid or minimize the influence of native language phonetic knowledge on English? Psychology can enlighten us to some degree. Working memory of human beings temporarily stores the information in a framework and manipulates the information. By contrast, long-term memory is the memory that is retained over a long period of time, such as life experiences, knowledge of how to do task, say, how to properly speak in a specific language. Long-term memory can provide sources for working memory.

During the process of speech production, speakers extract information from long-term memory to working memory and encode the information into a sound. Fauconnier (1994) holds that "Mental spaces are connected to long-term schematic knowledge". He also emphasizes "mental spaces operate in working memory but are built up partly by activating structures available from long-term memory" [7].

In order to embed the English schematic knowledge into students' long term memory, firstly, teachers are supposed to explain in detail the characteristics of each English phoneme, the difference between English vowel and Chinese finals, English consonants and Chinese initials. Make sure students can distinguish similar sounds in Chinese and English. Furthermore, teachers should also explain to students the differences between Chinese and English in terms of stress, syllable structure, rhythm, and other suprasegmentals.

Secondly, combined with the input of a large number of authentic speech materials and the input of real context, students are required to build a solid long-term memory of English knowledge by ways of practicing individual sounds, tones, rhythm, etc. repeatedly. With the intensive practice, when a student has a voice output task, he will automatically extract the English phonetic information from the long-term memory stored in the mental space and encode it. With the precise English phonetic knowledge in his English input mental space, the learner can effectively prevent the entering of information of Chinese phonetic system. In this way, the phonetic fossilization is expected to be transformed into standard and authentic English speech more quickly.

The current research is done with English majors as subjects. Although it can reveal many aspects of the phonetic fossilization of Chinese students, there may be other types of phonetic fossilization in other English learners of Chinese students. Hence, further researches should be done to find out more about phonetic fossilization in Chinese students.

\section{References}

[1] Selinker L. INTERLANGUAGE [J]. IRAL - International Review of Applied Linguistics in Language Teaching, 1972, 10(1-4):209-232.

[2] Fauconnier G, Turner M B. Conceptual Projection and Middle Spaces [J]. Social Science Electronic Publishing, 2008.

[3] Fauconnier G, Turner M. Conceptual Blending, Form and Meaning [J]. Recherches En Communication, 2003.

[4] Fauconnier G, Turner M. Conceptual Integration Networks [J]. Cognitive Science, 1998, 22(2):133-187.

[5] 王正元．概念整合理论及其应用研究 [M].北京：高等教育出版社， 2009 .

[6] 许余龙. 对比语言学概论 [M].上海: 上海外语教育出版社, 2005.

[7] Fauconnier,G. Mental Spaces. www.cogsci.ucsd.edu/ faucon/BEIJING/mentalspaces.pdf. 